\title{
Enfrentamento dos pais frente aos filhos prematuros e hospitalizados em UTI neonatal
}

\author{
Fernando Antônio Joaquim*, Mariana Freitas Comin, M.Sc.**
}

*Acadêmico do Curso de Enfermagem da Universidade do Extremo Sul Catarinense - UNESC, **Professora do Curso de Enfermagem da Universidade do Extremo Sul Catarinense - UNESC

\section{Resumo}

Trata-se de um estudo de abordagem qualitativa, do tipo descritiva exploratória, desenvolvido em uma unidade de terapia intensiva (UTI) neonatal, de um Hospital Materno Infantil localizado na região do Extremo Sul Catarinense, com 12 pais de recém-nascidos $(\mathrm{RN})$ prematuros. O objetivo foi identificar quais os principais sentimentos expressados pelos pais em relação à hospitalização dos filhos prematuros em UTI neonatal. Os dados foram levantados através da aplicação de entrevista semiestruturada. Como resultados, os participantes apresentavam um misto de medo e insegurança diante da internaçáo de seus filhos na UTI neonatal, mas, também, tinham os que sentiam alívio e esperança por estarem nessa unidade equipada e preparada para atender os $\mathrm{RN}$ prematuros. $\mathrm{O}$ estudo possibilitou concluir que fatores de risco como a idade, o nível socioeconômico baixo, a baixa escolaridade, o uso de substâncias entorpecentes como álcool e drogas ilícitas estão associados à prematuridade. E quanto ao enfrentamento dos pais diante de seus filhos prematuros internados em UTI neonatal, podemos concluir que, em quase sua totalidade, esses se encontram preparados e amparados para essa situaçáo, sendo esse reflexo de uma boa equipe multidisciplinar.

Palavras-chave: prematuro, unidade de terapia intensiva neonatal, Enfermagem.

\section{Abstract}

\section{Parents feelings of premature babies who were hospitalized in neonatal ICU}

This is a qualitative study with descriptive exploratory approach which was developed in a neonatal intensive care unit (ICU) of a Maternal and Infant Hospital in South Extreme region of Santa Catarina, with 12 parents of premature babies. The aim was to identify the main feelings parents expressed in relation to hospitalization of premature babies in ICU. Data were collected using a semi-structured interviewed. The results pointed out that the participants showed a mixture of fear and insecurity relating to their babies hospitalization in the neonatal ICU, but there are also others that felt relief and hope as this care unit is well-equipped and trained care staff to help premature babies. The study concluded that factors such as age, low socioeconomic status, low education, use of narcotic substances (alcohol and illicit drugs) are associated with prematurity. And it also concluded that most of the parents of these babies are prepared and had support to face their children hospitalization in the ICU, which showed that the multidisciplinary team is well trained.

Key-words: premature infant, neonatal intensive care unit, Nursing. 


\section{Resumen}

\section{Reacción de los padres frente a la hospitalización de recién nacido prematuro en $\mathrm{UCI}$ neonatal}

Se trata de un estudio cualitativo, descriptivo, exploratorio, desarrollado en una unidad neonatal de cuidados intensivos de un Hospital Materno Infantil ubicado en el extremo Sur de Santa Catarina, con 12 padres de bebés prematuros. El objetivo fue identificar los principales sentimientos manifestados por los padres con respecto a la hospitalización de sus hijos prematuros en la UCI neonatal. Los datos se obtuvieron mediante aplicación de entrevista semiestructurada. Los resultados apuntaron que los participantes sentían una mezcla de miedo e inseguridad frente a la hospitalización de sus hijos en la UCI neonatal, pero, también, había los que sentían alivio y esperanza por estar en esta unidad equipada y preparada para cuidar de recién nacidos prematuros. El estudio permitió concluir que los factores de riesgo como la edad, el nivel socioeconómico bajo, el bajo nivel educativo, el uso de sustancias estupefacientes tales como el alcohol y las drogas ilícitas, están asociadas con la prematuridad. Se concluyó también que la mayoría de los padres están preparados y fueron amparados para enfrentar la hospitalización de sus hijos en la UCI neonatal, por lo tanto demuestra el reflejo de un equipo multidisciplinario bien entrenado.

Palabras-clave: prematuro, unidad de cuidados intensivos neonatal, Enfermería.

\section{Introdução}

O momento do parto, para muitos, é algo sagrado e divino e é influenciado por muitos fatores. Historicamente o acompanhamento do trabalho de parto ocorria no ambiente domiciliar, no qual a mulher era assistida geralmente por uma parteira de confiança da família.

O nascimento prematuro é definido como aquele que ocorre até 37 semanas de gestação. Um recém-nascido $(\mathrm{RN})$ é considerado de baixo peso quando atinge um peso igual ou menor que $2.500 \mathrm{~g}$. Nascem anualmente no mundo, 20 milhôes de crianças prematuras. Destas, um terço morre antes de completar um ano [1].

Acredita-se que no ambiente hospitalar não há apenas os sentimentos de medo, insegurança, desespero e preocupaçôes por parte dos recém-nascidos (RN), mas também estes sentimentos refletidos nos pais, tendo este pensamento como objeto desta pesquisa.

Teve-se como objetivo da pesquisa identificar quais os principais sentimentos expressados pelos pais em relação à hospitalização dos filhos prematuros em UTI Neonatal. Esses problemas já preocupam profissionais da área da saúde, no entanto pensávamos em como ficariam esses pais, que sentimentos apresentariam diante de um filho prematuro e toda essa problematização, por isso iniciamos nossa pesquisa com a seguinte indagação: Quais os sentimentos e percepçóes dos pais em relação à necessidade de internação em UTI Neonatal de seus filhos prematuros?

\section{Material e métodos}

Foi desenvolvida uma pesquisa de abordagem qualitativa do tipo descritiva e exploratória que buscou conhecer os sentimentos e percepçóes dos pais de recém-nascidos prematuros hospitalizados em Unidade de Terapia Intensiva neonatal, na tentativa de compreender com maior aprofundamento estas sensaçôes para, então, estabelecer novas alternativas de cuidado aos pais.

Os dados foram coletados por meio de entrevista semiestruturada aplicada pelo próprio pesquisador ao término da visita dos pais aos seus filhos na UTIN. As entrevistas foram previamente agendadas, sendo realizadas com doze (12) pais de $\mathrm{RN}$ prematuros no período de 17 de abril a 31 de maio de 2012.

O estudo foi desenvolvido na UTI neonatal de um Hospital Materno infantil localizado na região do Extremo Sul Catarinense. O projeto foi submetido ao Comitê de Ética em Pesquisa da instituição de ensino e seguiu o disposto pela resolução 196/96. A pesquisa foi iniciada somente depois da aprovação do comitê, com parecer de no 21225 . 


\section{Resultados}

\section{Etapa I: categorizaçáo dos dados}

Participaram deste estudo doze (12) pais, de nível socioeconômico variado e que estavam com seus filhos RNs internados. A idade dos pais teve uma variação entre 18 e 29 anos, e, a maioria dos pais tinha apenas um filho. Ainda, a metade das máes estava em uma faixa etária acima de 24 anos e a renda em sua maioria era em média de 1 a 3 salários mínimos.

Percebeu-se que 05 mulheres tiveram algum tipo de aborto antes desta gestação. Há mulheres que podem apresentar abortos sucessivos, o que pode abalar emocionalmente e interferir no relacionamento com seu cônjuge. Sendo que todos os partos foram cesarianos.

Evidenciamos que a idade gestacional variou entre 31 e 36 semanas e percebemos que a qualidade da atenção pré-natal foi insatisfatória.

Relacionado aos vícios da mãe, percebemos que seis dessas máes negam qualquer tipo de vícios, no entanto a metade das entrevistadas (6) são preocupantes pelo fato de serem usuárias tanto de drogas lícitas como ilícitas (3 tabagistas), como de drogas lícitas (2 usuárias de maconha e 1 usuária de maconha e cocaína), podendo esse fato estar relacionado ao estado atual de seus bebês. Quanto às comorbidades das mães, apenas duas (2) referiram ter diabetes mellitus. Discorre-se a pesquisa com a categorização das respostas a seguir.

\section{Etapa II: categorizaçáo das respostas}

Em se tratando de acontecimento com o RN, percebeu-se que os participantes tinham a intenção e a vontade de levarem seus filhos para casa, isso está evidente em algumas falas a seguir:

"Imaginava tudo diferente parto normal, pegar ele no colo e levar para casa." (P10)

"Queria levar nosso filho para casa, para o quartinho dele que montamos com tanto amor." (P12)

Quando questionados sobre as informaçóes recebidas, e se essas foram suficientes para sua compreensão, percebemos que as mesmas foram repassadas pelos médicos e enfermeiras, e nenhum dos participantes apresentou sugestóes para melhorias, concordando que essas são suficientes. Além disso, conheciam o funcionamento da UTI e o estado de saúde do seu filho. Podendo ser percebidas nos relatos que seguem.

"Recebi as informaçôes da equipe de enfermagem e dos médicos, está bem bom não tenho que reclamar." (P3)

"Nas orientaçôes que recebemos, a equipe esclarece tudo, que não podemos ficar o tempo todo na visita, estão nos passando tudo sobre o estado dele." (P3)

"Sei que meu filho está aqui por ter baixo peso e ser prematuro." (P6)

Quando indagados sobre a internação do RN na UTI neonatal, os participantes expressaram sentimentos de culpa, impotência e perda iminente. No momento que sabem que ele precisa ficar internado o sonho é desfeito e tudo que foi planejado desmorona. Ficando claro no comentário a seguir:

"Eu me senti impotente, um nada." (P4)

"Nos três dias que fiquei internada não pude estar com o meu bebê, me

senti um lixo." (P12)

Mesmo passando por um momento táo difícil percebemos que os participantes expressavam sentimentos de satisfação e alívio ao verem seu pequeno bebe respirando ainda com vida. Tal fato fica evidente no que diz os participantes.

"Eu senti alívio de ver meu filho com vida." (P1)

"Senti-me impotente, chorei muito, e quando vi meu filho lutando pela vida comecei a ver o mundo diferente. “(P11)

$\mathrm{Na}$ instituição pesquisada, a visita na UTI neonatal acontece três vezes ao dia, sendo no período matutino e noturno 1 hora de visita, já no período vespertino a mesma é prolongada por mais 1 hora, ficando o RN na companhia de seus pais por 2 horas. Porém, nos finais de semana, é destinado 15 
minutos do tempo para os avós dos bebês, talvez esse seja o único ponto que se discorda, pois se acredita que a interação entre toda família seria importante na recuperação do $R N$.

Dos participantes a media de visita ficou em torno de duas a três vezes por dia, exceto P2 que visita seu filho apenas uma vez. Dos $12 \mathrm{RN}$ do estudo oito deles recebiam visitas de suas avós nos finais de semana.

Um dos objetivos desta pesquisa foi de identificar as orientaçóes fornecidas aos pais de RN prematuros, essas se apresentaram eficazes conforme observado nas falas a seguir:

"A equipe é ótima meu filho está em boas mãos.” (P4).

"Nossa! os técnicos de enfermagem e os médicos são muito bons. É uma família para nós. "(P5)

Analisando a relação conjugal de nossos participantes, percebemos que mesmo sendo quase a totalidade favorável a essa situação, dois desses nos preocuparam pelo fato de terem enfraquecido suas relaçóes durante esse período difícil, pois se culparam e tentaram buscar a culpa no outro por essa situação desconfortável. Tornando esse momento ainda mais difícil. Por isso dividimos essa categoria em duas subcategorias, sendo uma positiva e outra negativa, sendo essas apresentadas a seguir.

\footnotetext{
"Nossa relação está razoavelmente bem, mais meu marido me culpa pela criança estar na UTI." (P3)

"No início bateu um desespero entre nós dois, quase nos separamos. Conversamos muito de tudo que nós passamos na vida, e agora estamos mais unidos." (P5)
}

\section{Discussão}

As causas mais importantes de mortalidade infantil, no Brasil, são a anóxia perinatal, as infecçóes e a imaturidade (bebê com menos de $1.000 \mathrm{~g}$. ao nascer) seguindo das malformaçóes congênitas e doença pulmonar [2]. Entre os 130 milhóes de crianças que nascem no mundo anualmente, cerca de 4 milhóes morrem ainda no período neonatal. A autora assegura que desses óbitos, 99\% acontecem em regióes com baixa renda [3].

Geralmente, a primeira visita da mãe ao seu filho internado na UTI Neonatal é o primeiro contato depois do nascimento, tratando-se de uma ocasião de significado especial para ambos, tornando-se o momento em que ocorre o reconhecimento mútuo através da voz, do toque, do olhar. De modo a evitar maiores dificuldades, nesse primeiro encontro devem ser tomados diversos cuidados para o pronto estabelecimento do vínculo afetivo mãe-filho [4].

A expectativa de ter filhos perfeitos e saudáveis é comum para todos os pais, o que não foi diferente para as mães participantes desta pesquisa na qual o nascimento de um filho prematuro, em condiçóes que implicaram em hospitalizaçáo, representou a ruptura na dinâmica do nascimento de ter um bebê saudável e poder levá-lo para casa poucos dias após o nascimento [5].

O acolhimento à família é importante para promover a saúde de todos os seus membros e garantir ao bebê um espaço que vai auxiliá-lo em seu desenvolvimento.

O curso do desenvolvimento dos RN de baixo peso está firmemente atado às condiçóes socioeconômicas nas quais eles vivem, o que pode ser observado também neste estudo. As evidências mostraram que o ambiente familiar da criança estava mais frequentemente implicado em um pobre desenvolvimento do que qualquer problema biológico ou complicaçóes médicas em particular.

"Os estudos sobre ambiente passaram a usar marcadores mais refinados, que estão mais próximos de revelar as verdadeiras experiências da criança (interaçóes mãe-bebê, entrevistas com os pais, eventos e interaçóes domésticas). [...] As pesquisas mudaram de um exame quase descontextualizado para modelos ecológicos complexos - incluindo um olhar mais detalhado para a ecologia familiar e especificamente aqueles que podem afetar a qualidade de cuidados que a criança recebe (stress, suporte social, personalidade e competência dos pais)" [6].

É importante salientar que nos resultados obtidos observou-se que a equipe de saúde, assim, como é função de uma equipe multidisciplinar, informa tudo que acontece com os pacientes, nesse caso os RN, que estão hospitalizados e aos seus cuidados.

Humanizar a assistência neonatal é atender de maneira individualizada as necessidades do recém-nascido e de sua família, visando a ótima qualidade de cuidado, independente do resultado de sobrevida 
ou a morte do recém-nascido. O cuidado humanizado deve ser capaz de transmitir aos pais o sentimento de solidariedade e de respeito à sua dor [7].

É de fundamental importância que à equipe de enfermagem da UTIN busque medidas que minimizem o sofrimento e a dor do bebê e sua família. A equipe de profissionais que trabalha na UTIN, em especial a enfermagem, é submetida a vários estímulos estressantes. $\mathrm{O}$ ritmo de trabalho é intenso e cansativo [8].

O olhar não é o suficiente para a construção do apego, é preciso tocar, acariciar, conhecer o bebê e suas reaçóes pelo toque, sendo essa uma forma de aproximação importante durante a hospitalização, diminuindo um pouco a ansiedade característica dessa situação. Desde modo, mesmo, mesmo que o recém-nascido ainda não esteja em condiçôes de receber os cuidados prestados por sua mãe devido ao seu quadro clinico, os profissionais devem incentivá-las a tocar e pegar seu filho no colo, para que possam vivenciar a aproximação, tornando as visitas na UTI motivadoras e favoráveis ao vínculo familiar [9].

Pode ser evidenciado na pesquisa que houve um sentimento de medo e alegria ao mesmo tempo. Para os pais, a UTIN é um ambiente de esperança e de medo. Esperança por saber que este é um local preparado para atender melhor o seu filho e aumentar as chances de sobrevida. Medo, por saber dos riscos inerentes aos pacientes que vão para este ambiente, e ainda, sentimentos de frustração, por não estarem, em geral, preparados para esta situação [8].

Em um primeiro momento mãe e bebê estão submetidos a uma série de restriçóes em função da imaturidade e instabilidade do bebê, o que dificulta o contato. Diante dessa situação, terão que redescobrir um caminho de aproximação e contato, o que promoverá a constituição e desenvolvimento do bebê enquanto recém-nascido.

Os pais de RN são pessoas que ficam debilitadas pelo problema que estão passando com seus bebês. Ao realizarem a primeira visita ao recémnascido, o pai que idealizou o bebê perfeito se depara com a condição angustiante de ver seu filho necessitando de cuidados advindos de outras pessoas que não são seus parentes, como mãe e o pai. Isso é causador da dependência que gera esta situação, tornando a equipe que presta o cuidado um elo de ligação entre a família e o recém-nascido. É através dela que os pais saberão como foi o dia do bebê e qual é a sua evolução dia após dia.
A assistência de enfermagem deve valorizar a interação profissional-família, estabelecer confiança, adequada comunicação e cooperação para realização de um cuidado efetivo [10].

Pensando assim, a visita ao recém-nascido é extremamente importante, pois o bebê se sentirá amado e desejado, e terá uma melhora e desenvolvimento mais rápido.

O casamento é ainda a fonte estabilizadora das sociedades, por ser a base para geração das famílias é na sua acepção fidedigna. É onde as virtudes humanas são iniciadas e aprofundadas.

Sabe-se que toda criança ao nascer pertence a um grupo familiar e está ligada diretamente a uma cultura. $\mathrm{O}$ estado de saúde depende de uma série de fatores relacionados aos pais, ao recém-nascido e ao ambiente onde ele vai viver, estando ligado ao fator socioeconômico da família. A gestação e o nascimento são considerados um processo social, uma vez que afetam a relação entre o marido e a mulher e o meio em que estão inseridos [9].

Quando a gestação é interrompida pelo nascimento prematuro, os pais do recém-nascido vivem uma situação de crise. Convivem com uma "reação de luto" pelo filho perfeito que não tiveram e necessitam tempo e apoio para que possam aceitar seu filho real. Seus sentimentos são de revolta, culpa, angústia, tristeza, medo e esperança $A$ rede familiar recebe o impacto e tenta se adaptar desenvolvendo estratégias dentro e fora de seu ambiente, para lidar com a nova situação A maioria dos pais de recém-nascidos internados em UTI Neonatal sofre estresse emocional. É necessário entender o que se passa com eles. Os intensivistas devem ter uma atitude não julgadora, entender as preocupaçóes, o comportamento dos pais e os sentimentos encobertos da família [11].

A Enfermagem se insere nessa temática, tendo como objeto de cuidado o ser humano, o qual é imbuído de características que poderão diversificar este cuidado, conforme as necessidades afetadas. $\mathrm{O}$ cuidado é considerado a essência da Enfermagem e, como tal, é relevante que seja prestado de forma humanizada ao indivíduo, à família e à comunidade [12].

\section{Conclusão}

Faz parte da lei da vida, nascer, crescer e produzir bons frutos, isso é o que se escuta durante anos, quando o assunto é ser vivo. Porém, quando relacionado ao ser humano, pode-se complementar 
dizendo que após gerar filhos, o apropriado seria levar para a casa e cuidar até que esse siga seu caminho. Mas não foi exatamente isso que se observou neste estudo, mães foram precocemente separadas de seus filhos, pais náo conseguiram segurá-los no colo, tudo por conta da prematuridade.

A hospitalização do filho na UTIN foi representada inicialmente pela quebra do simbolismo tradicional do nascimento seguida de situaçôes difíceis e conflitantes entrelaçadas ao desafio de adequação à rotina estressante da UTIN e os percalços inerentes à trajetória na busca da sobrevivência do filho. Nesta vivência, inserem-se sentimentos como choque, culpa, insegurança, medo, tristeza, alegria e esperança.

Cabe aqui registrar a necessidade de dar continuidade a este trabalho, priorizar a atenção às mulheres neste período da vida, principalmente no que diz respeito à assistência ao pré-natal, a fim de identificar precocemente possíveis riscos para o feto e a máe, proporcionando uma implementaçáo de assistência de enfermagem eficaz.

\section{Referências}

1. Cascaes AM, Gauche H, Baramarchi FM, Borges CM, Peres KG. Prematuridade e fatores associados no Estado de Santa Catarina, Brasil, no ano de 2005: análise dos dados do Sistema de Informaçóes sobre Nascidos Vivos. Cad Saúde Pública 2008;24:1024-32.

2. Segre CAM. Perinatologia: fundamentos e prática. São Paulo: Sarrier; 2002.
3. Zanini GA, Moraes AB, Giugliani ERJ, Riboldi J. Determinantes contextuais da mortalidade neonatal no Rio Grande do Sul por dois modelos de análise. Rev Saúde Pública 2011;45(1):79-89.

4. Carvalho CL, La Torre MPS, Oliveira AFVR, Quirino $\mathrm{MD}$. Sentimentos maternos na visita ao recém-nascido internado em uma unidade de terapia intensiva. Rev Ciênc Cuid Saúde 2004;3:267-75.

5. Souza NL, Araújo ACPF, Costa ICC, Carvalho JBL, Silva MLC. Representações de mães sobre hospitalização do filho prematuro. Rev Bras Enferm 2009;729-33.

6. Bradley RH, Casey PH. Family environment and behavioral development of low birthweight children. Developmental Medicine and Child Neurology 1992;(34):822-33.

7. Naganuma M, Reichert MCF, Kakehashi TY, Barbosa VL, Ikezawa MK, Fogliano RRF. Procedimentos técnicos de enfermagem em UTI neonatal. São Paulo: Atheneu; 1995;168.

8. Reichert APS, Lins RNP, Collet N. Humanização do cuidado da UTI Neonatal. Rev Eletrônica Enferm 2007;09(1):200-13.

9. Medeiros HMF, Antunes VP. Participação dos pais na assistência ao recém nascido internado na UTI neonatal. São Paulo: Vidya; 2003.

10. Wernet M, Angelo M. A enfermagem diante das mães na Unidade de Terapia Intensiva Neonatal. Rev Enferm UERJ 2007;15(2):229-35.

11. Pereira SMP, Cardoso MHC. A metodologia utilizada em estudos que envolvem ecos da prematuridade na história da família. Rev Bras Crescimento Desenvolv Hum 2005; 15(3):74-83.

12. Cardoso MVLML, Souto KC, Oliveira MMC. Compreendendo a experiência de ser pai de recém-nascido prematuro internado na unidade neonatal. Rev RENE 2006;7(3):49-55. 